\title{
PRODUCTION OF THE ENZYME CYCLODEXTRIN GLYCOSYLTRANS- FERASE USING DIFFERENT FERMENTATION TECHNIQUES
}

\author{
RÉKa CZINKÓCZKY AND Áron NÉMETH *1 \\ ${ }^{1}$ Department of Applied Biotechnology and Food Science, Budapest University of Technology and \\ Economics, Múegyetem rkp. 3, Budapest, 1111, HUNGARY
}

\begin{abstract}
Cyclodextrins produced by cyclodextrin glycosyltransferase (CGTase) are widely used in the pharmaceutical industry to improve the solubility of drug substances as well as protect them against oxidation. The use of this enzyme in the cosmetics industry is also significant. CGTase is an enzyme that belongs to the $\alpha$-amylase family, which is part of the group of non-Leloir glycosyltransferases. Enzyme-catalysed transglycosylation reactions may involve cyclization, coupling and disproportionation processes. The enzyme CGTase is mostly used to produce cyclodextrins (CDs). CGTase can produce $\alpha-, \beta$ - and $\gamma$-CDs during transglycosylation reactions, depending on the number of glucopyranose units involved $(6,7$ or 8). The enzyme CGTase can also be used for enzymatic bioconversion, e.g., in the development of alternative sweeteners, where the bitter aftertaste of the product is reduced during the enzymatic bioconversion of steviol glycosides, thereby obtaining an even sweeter and more advantageous material. In our research, the enzyme CGTase was produced using different fermentation techniques to compare the activity and amount of CGTase produced by each process and optimize the subsequently planned scale-up. In our studies, the strain DSM 13 of Bacillus licheniformis was used, which produced CGTase extracellularly. During the experiments the batch, fed-batch and semi-continuous fermentation techniques were compared in terms of enzymatic production. All cultivation processes were carried out in a desktop lab scale fermenter.
\end{abstract}

Keywords: Cyclodextrin glycosyltransferase, fermentation, cyclodextrins, Bacillus licheniformis

\section{Introduction}

Cyclodextrin glycosyltransferase (CGTase, EC 2.4.1.19) is a starch-degrading enzyme, which is a member of the $\alpha$-amylase family. The formal name of CGTase is [1,4- $\alpha$ D-glucan 4- $\alpha$-D-(1,4- $\alpha$-glucano)-transferase(cyclizing). Kuriki et al. [1] reported that CGTase has the same four highly conserved regions as the $\alpha$-amylases. CGTase catalyses four kinds of transglycosylation reactions (Fig. 1): cyclization, coupling, disproportionation and hydrolysis. These reactions are all transglycosylations, in which cyclization is intramolecular, coupling and disproportionation are intermolecular, and hydrolysis is the conversion of sugar to $\mathrm{H}_{2} \mathrm{O}$ [2]. The formation of cyclodextrin (CD) by the enzyme CGTase is an intermolecular transglycosylation reaction [3].

Many microorganisms are capable of producing CGTase, e.g., Bacillus macerans [4, 5], Bacillus amyloliquefaciens [6], Bacillus clarkii [7], Bacillus megaterium [8], Bacillus subtilis [9], Bacillus licheniformis [10,11], Bacillus firmus [12,13], Bacillus circulans [14,15], Bacillus ohbensis [16, 17], Geobacillus stearothermophilus [18], Thermoanaerobacter sp. [19], Klebsiella pneumoniae, and Klebsiella oxytoca [20].

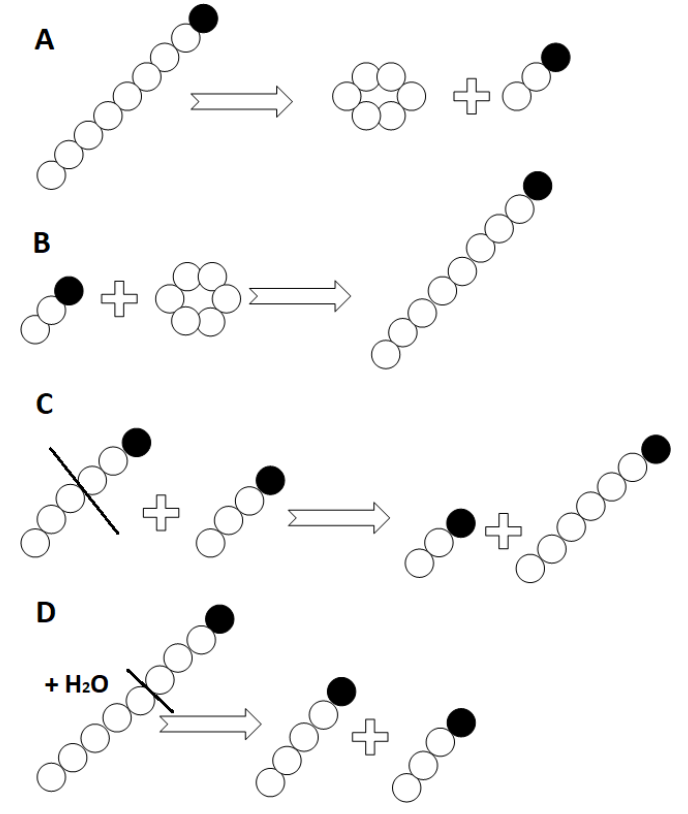

Figure 1: CGTase-catalysed reactions: A: cyclization, B: coupling, C: disproportionation, D: hydrolysis

*Correspondence: naron@f-labor.mkt.bme.hu 

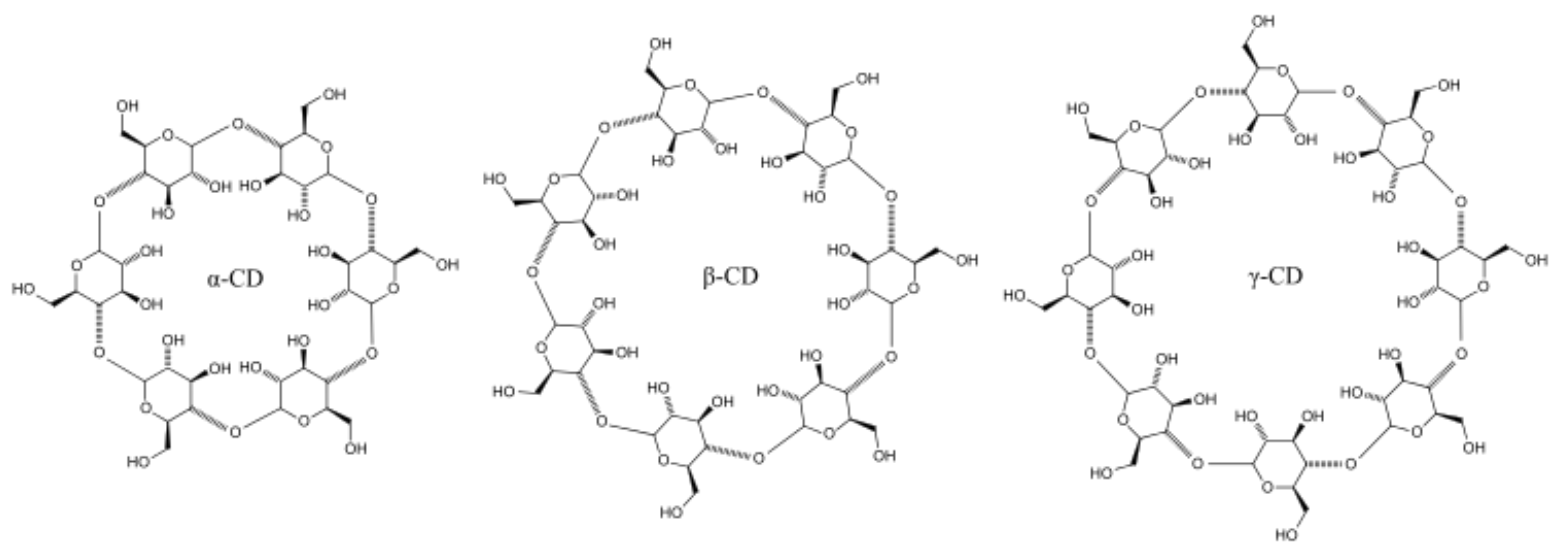

Figure 2: General structure of cyclodextrins (n: number of glucopyranose units, $n=6 \alpha$-CD, $n=7 \beta$-CD, $n=8 \gamma$-CD) (Figure adapted from: https://commons.wikimedia.org/wiki/File:Cyclodextrin.svg CC BY-SA 3.0) (08.07.2019) )

The molecular weight of CGTases may vary from 60 to $110 \mathrm{kDa}$, typically its proteins have a mass of $75 \mathrm{kDa}$ [21]. The most important demand of metal ions for them is $\mathrm{Ca}^{2+}$, which protects the protein against heat denaturation. Most CGTases are strongly inhibited by $\mathrm{Zn}^{2+}, \mathrm{Cu}^{2+}$ and $\mathrm{Fe}^{2+}$ [22].

Cyclodextrins, produced from starch or its derivatives via enzymatic conversion, proceed through an intramolecular transglycosylation reaction using CGTases and to a lesser extent $\alpha$-amylases [3]. They are cyclic oligosaccharides composed of $\alpha$-1,4-glycosidic-linked glucosyl residues [23]. Three different types of cyclodextrins exist and are characterised according to the number of glucosyl residues in the molecule: $\alpha$-, $\beta$ - and $\gamma$ cyclodextrins consist of 6,7 and 8 glucose units, respectively (Fig. 2). Cyclodextrins are cyclic molecules with a hydrophilic exterior and a hydrophobic cavity that enables them to form specific inclusion complexes with small hydrophobic molecules [24]. Cyclodextrins are chiral non-reducing oligosaccharides. Glucose is the decomposition product of all cyclodextrins in acidic solutions.

The rate of hydrolysis follows the order of $\gamma>$ $\beta>\alpha$. Under acidic conditions, cyclodextrins are more slowly hydrolyzed than maltooligosaccharides. The glycosidic bonds in the cyclodextrins can be hydrolyzed by $\alpha$-amylase, but $\beta$-amylase is unable to perform this hydrolysis. The rate of enzymatic hydrolysis is the fastest for $\gamma-\mathrm{CD}$, followed by $\beta$ - then $\alpha$-CD. All CDs are very stable and soluble in alkaline solutions at high $\mathrm{pH}$. CDs are more resistant to acid or alkaline degradation than starch. CDs do not even degradate at temperatures as high as that of caramelization $\left(>200^{\circ} \mathrm{C}\right.$, sterilization) under both dry or aqueous conditions of between pH 2 and 12 . They are also stable up to $250^{\circ} \mathrm{C}$ under an inert atmosphere of, for example, nitrogen [20, 25, 26].

The widespread use of cyclodextrins is due to their specific structure. Since each guest molecule is uniquely surrounded by the CD (or one of its derivatives), it is microencapsulated from a molecular microscopic point of view. This can result in beneficial changes to the chemical and physical properties of guest molecules, e.g., light- or oxygen-sensitive materials can be stabilized; very volatile substances fixed; the chemical reactivity of molecules modified; the solubility of materials improved; changes between phases achieved from liquid substances into powders; degradation of microorganisms avoided; bad smells and tastes masked; and pigments or colors of materials coated. As a result of these characteristics, CDs (and their derivatives) can be used in analytical chemistry, agriculture, the pharmaceutical as well as food industries and other masking areas. CGTase can be used for the transglycosylation of stevioside to rebaudioside through which the edulcorant quality can also be improved by increasing the substitution of steviol glycoside with the help of cornstarch hydrolyzate and CGTase [27-30].

\section{Materials and Methods}

\subsection{Cultivation of the bacteria}

The applied bacterial strain was Bacillus licheniformis B.01470 (DSM 13) purchased from the National Collection of Agricultural and Industrial Microorganisms in Hungary. Bacillus licheniformis is a Gram-positive, rodshaped, endospore forming, facultatively anaerobic bacteria. Nutrient agar was used to maintain the bacterium in Petri dishes [31]. In our research, three types of fermentation techniques for the production of CGTase were compared: batch, fed-batch, and semi-continuous fermentation techniques. All cultivation processes were carried out in a benchtop lab scale fermenter (Fig. 3) (Biostat Q, B. Braun Biotech International, Germany). In the fed-batch fermentation, after 24 hours $15 \mathrm{v} / \mathrm{v} \%$ of the medium was fed into the bioreactor. During the semi-continuous fermentation at the end of each cycle, $80 \%$ of the broth was replaced by fresh media.

For the experiments in the bioreactor, Horikoshi II medium was used for the cultivation of bacteria containing $1.0 \%$ soluble starch, $0.5 \%$ peptone, $0.5 \%$ yeast extract, $0.1 \% \mathrm{~K}_{2} \mathrm{HPO}_{4}, 0.02 \% \mathrm{MgSO}_{4} \cdot 7 \mathrm{H}_{2} \mathrm{O}$, and $1.0 \%$ $\mathrm{Na}_{2} \mathrm{CO}_{3}$ (all concentrations are given in w/v in distilled water) [32]. 


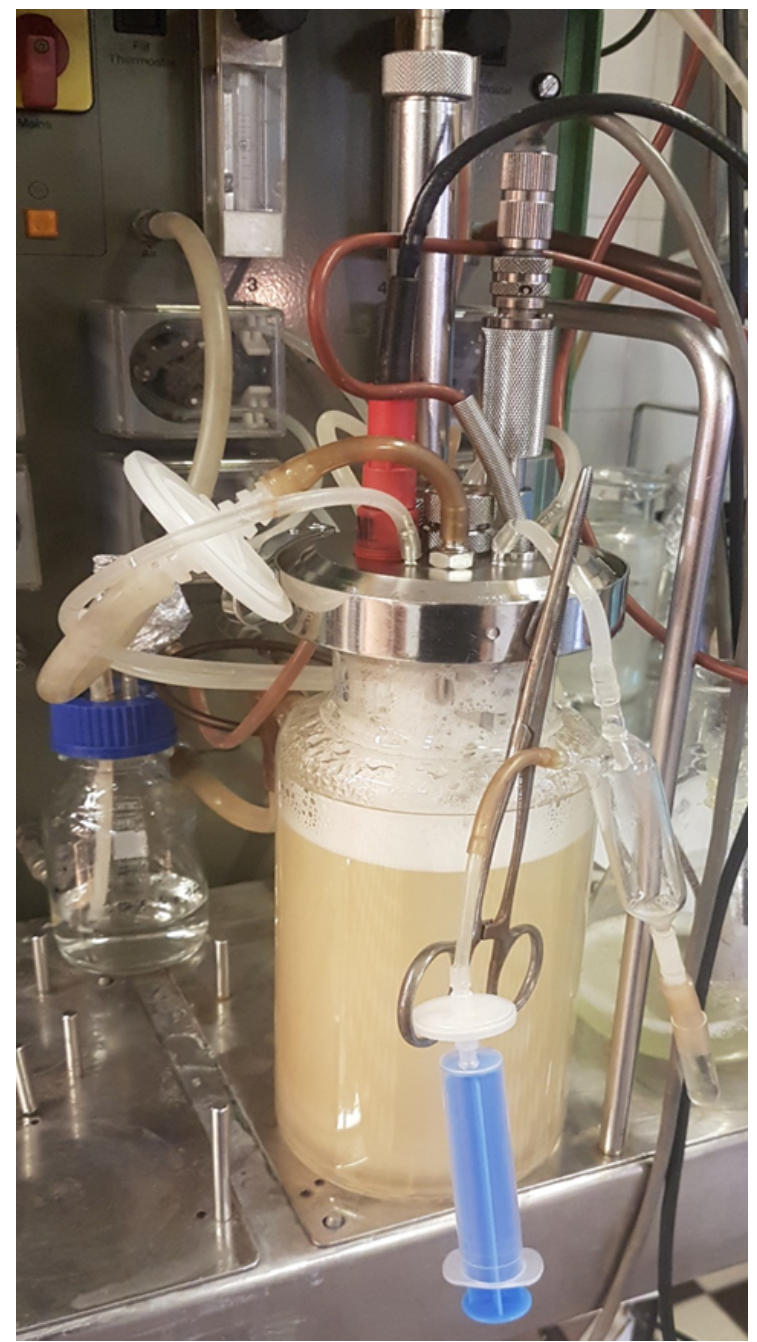

Figure 3: The bioreactor used in the experiments

\subsection{The modelling of microbial growth}

In order to monitor the growth of bacterial cells, samples were taken during fermentations and the optical density (OD) measured at $600 \mathrm{~nm}$.

Microbial growth is described by

$$
\mu_{x}=\frac{1}{x} \frac{\mathrm{d} x}{\mathrm{~d} t},
$$

where $\mu_{x}$ is the specific growth rate of the microbe. It was evaluated through fitting the generalized logistic function

$$
Z=\frac{Z_{\max }}{1+\exp \left(a+b t+c t^{2}+d t^{3}\right)}
$$

to the measured cell dry weight (CDW) values (calculated from at OD600). To fit the curve, SigmaPlot Version 12.0 software was applied. If the coefficient of determination $\left(R^{2}\right)$ was not high enough, the last two members of the generalized logistic function were omitted resulting in

$$
Z=\frac{Z_{\max }}{1+\exp (a+b t)},
$$

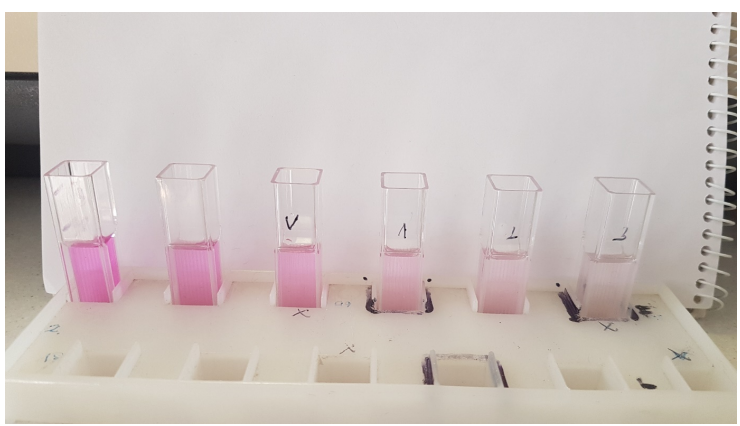

Figure 4: Colorimetric analysis of CGTase activity

which also corresponds to the modified Monod model. The derivative of the fitted function is

$$
\frac{\mathrm{d} Z}{\mathrm{~d} t}=-Z\left(1-\frac{Z}{Z_{\max }}\right) \frac{\mathrm{d} H}{\mathrm{~d} t}
$$

where

$$
\frac{\mathrm{d} H}{\mathrm{~d} t}=b+2 c t+3 d t^{2}
$$

is the derivative of the internal function. The auxiliary variable $Z$ in Eq. 2, 3, and 4 was $x$ (biomass in $\mathrm{g} / \mathrm{L}$ ), $S$ (substrate in $\mathrm{g} / \mathrm{L}$ ), and $P_{i}$ (product in $\mathrm{g} / \mathrm{L}$ ), respectively, while $Z_{\max }$ was $x_{\max }, S_{0}$ and $P_{i, \max }$, respectively. If the fit was successful, then, by using determined constants of the model, the velocities and specific growth rates could be calculated by derivation from Eq. 4 .

\subsection{Measurement of CGTase activity}

During the fermentations, samples were regularly extracted into Eppendorf tubes, which were centrifuged at $12,000 \mathrm{rpm}$ for 6 minutes, then the cell-free supernatants were used to determine the enzyme activity.

The measurement of extracellular CGTase activity was adapted from the method of Kaneko et al. [33] with slight modifications (with a reduced concentration of phenolphtalein). The colorimetric reaction (Fig. 4) was measured by a spectrophotometer at $550 \mathrm{~nm}$.

The experiments were conducted in $15 \mathrm{ml}$ centrifuge tubes in a water bath at $40^{\circ} \mathrm{C}$. First, $4.5 \mathrm{ml} 50 \mathrm{mM}$ Tris$\mathrm{HCl}$ buffer $(\mathrm{pH}=9)$ was added containing a $1 \%(\mathrm{w} / \mathrm{v})$ water-soluble starch suspension, then $0.5 \mathrm{ml}$ of cell-free supernatant containing the extracellular CGTase enzyme was introduced and homogenized thoroughly with a vortex mixer.

Then four $0.5 \mathrm{ml}$ samples were taken from each tube which were boiled for 5 minutes to inactivate the enzyme. The boiled samples were transferred into $2 \mathrm{ml} \mathrm{cu}-$ vettes that contained a staining solution $(1.2 \mathrm{ml} 0.06 \mathrm{mM}$ phenolphthalein in $0.5 \mathrm{M} \mathrm{Na}_{2} \mathrm{CO}_{3}$ solution). Four absorbances at $550 \mathrm{~nm}$ of a given assay were plotted against time and the gradient ( $\mathrm{mmol} / \mathrm{min}$ ) converted into enzyme activity with the help of a molar extinction coefficient $\left(32,263 \mathrm{M}^{-1} \mathrm{~cm}^{-1}\right)$ resulting in the CGTase activity in unit/ml supernatant. 


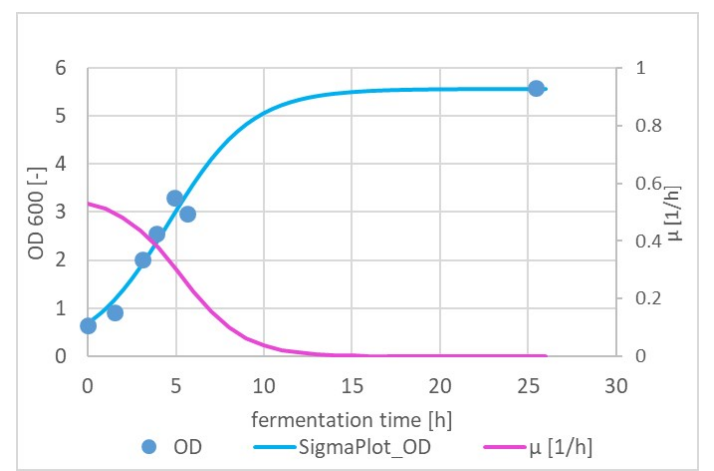

Figure 5: Microbial growth during the batch fermentation

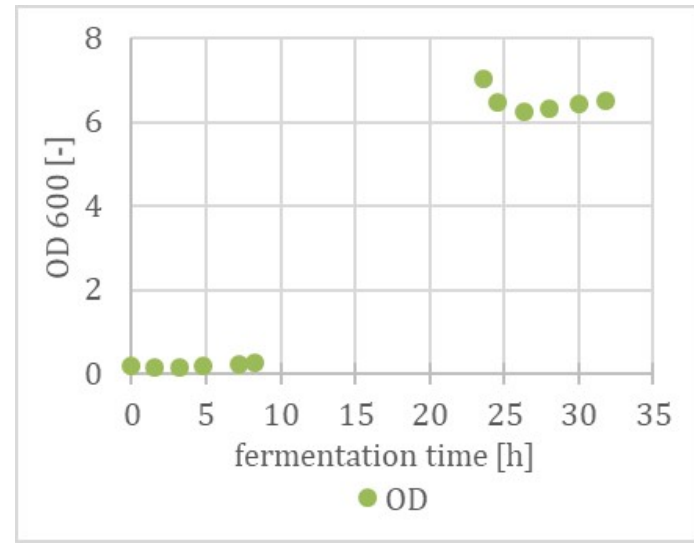

Figure 6: Microbial growth during the fed-batch fermentation

\section{Results and Discussion}

\subsection{Batch fermentation}

Fig. 5 shows the microbial growth during the batch fermentation and also represents the changes in the specific growth rate. The maximum value of the specific growth rate was $0.531 / \mathrm{h}$. At the end of the fermentation, the final activity of CGTase was $0.3 \mathrm{U} / \mathrm{ml}$ and the productivity was $11.8 \mathrm{mU} /(\mathrm{ml} \mathrm{h})$.

\subsection{Fed-batch fermentation}

Fig. 6 represents microbial growth during the fed-batch fermentation. Unfortunately, due to poorly scheduled sampling, it was not possible to adjust the generalized logistic equation, therefore, it was impossible to calculate the specific growth rate. A fresh medium of $15 \%$ was injected after 24 hours. The final enzyme activity was 0.5 $\mathrm{U} / \mathrm{ml}$ and the enzyme productivity was $12.3 \mathrm{mU} /(\mathrm{ml} \mathrm{h})$.

\subsection{Semi-continuous fermentation}

The semi-continuous fermentation is shown in Fig. 7, which consisted of 3 cycles. The highest value of the maximum growth rate was during the first cycle $(0.51 / \mathrm{h})$. As the fermentation progressed, the maximum specific growth rate decreased.

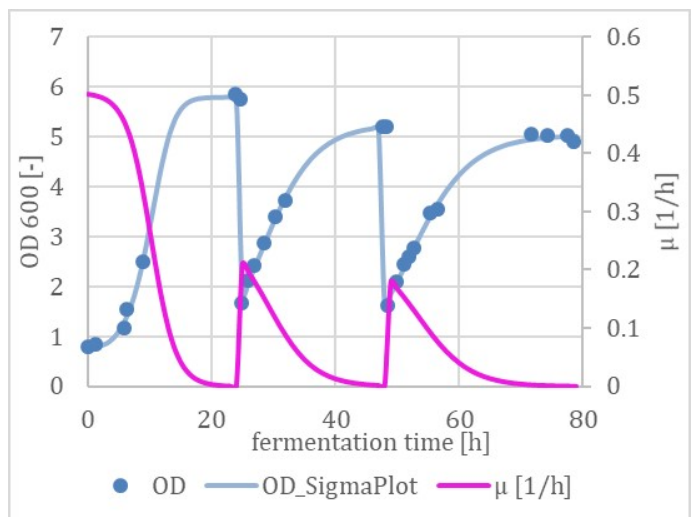

Figure 7: Optical density and specific growth rate changes during the semi-continuous fermentation

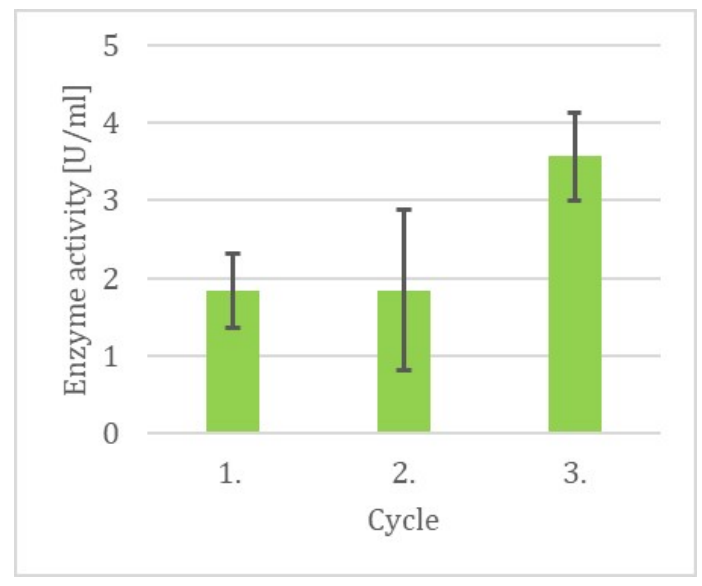

Figure 8: CGTase activities at the end of each cycle

Fig. 8 shows that the enzyme activity of CGTase increased as the fermentation progressed.

\subsection{Comparison of the different fermentation techniques}

Table 1 summarizes the enzyme activities and productivities achieved by each fermentation technique. The maximum specific growth rates reached in the batch and semicontinuous fermentations were approximately the same, which is characteristic of when the microorganism can multiply.

The enzyme activities at the end of the fermentations

Table 1: Comparison between the results of the different fermentation techniques

\begin{tabular}{cccc}
\hline Type & $\begin{array}{c}\mu_{\max } \\
{[1 / \mathrm{h}]}\end{array}$ & $\begin{array}{c}\text { Final } \\
\text { enzyme } \\
\text { activity } \\
{[\mathrm{U} / \mathrm{ml}]}\end{array}$ & $\begin{array}{c}\text { Productivity } \\
{[\mathrm{mU} /(\mathrm{ml})]}\end{array}$ \\
\hline $\begin{array}{c}\text { Batch } \\
\text { Fed-batch }\end{array}$ & 0.53 & 0.3 & 11.8 \\
$\begin{array}{c}\text { Semi- } \\
\text { continuous }\end{array}$ & 0.50 & 2.4 & $29.95 \pm 0.3$ \\
\hline
\end{tabular}


rose as the complexity of the fermentation technique increased. While the fed-batch fermentation elongated the declining phase of the microbial growth cycle, in the semi-continuous fermentation technique an attempt was made to operate in the exponential growth phase. It is assumed that this difference caused the higher activity and productivity in the case of the semi-continuous fermentation.

\section{Conclusion}

In our experiments, the effect of the fermentation technique on the activity of the produced enzyme CGTase was investigated. There was no significant difference between the activities of the produced CGTase and productivities of the systems when the batch and fed-batch fermentations were compared. In contrast, bacteria produced a much more active enzyme during the semi-continuous fermentation, moreover, the productivity of this system was also significantly higher than that of the other two fermentation techniques.

From the results, it can be assumed that the microbes produce the enzyme during the exponential growth phase, since no significant difference was observed between the batch and fed-batch fermentations. Meanwhile, a repeated exponential growth phase resulted in a much higher activity and productivity. This suggests that CGTase production follows growth associated-type product formation.

\section{Acknowledgement}

The research was supported by the Gedeon Richter's Talentum Foundation, founded by Gedeon Richter Plc. (Gedeon Richter PhD fellowship).

\section{REFERENCES}

[1] Kuriki, T.; Imanaka, T.: The concept of the $\alpha$ amylase family: Structural similarity and common catalytic mechanism, J. Biosci. Bioeng. 1999 87(5), 557-565 DOI: 10.1016/S1389-1723(99)80114-5

[2] Kobayashi, S.: Cyclodextrin producing enzyme (CGTase) in Park, K.-H.; Robyt, J. F.; Choi, Y.D. (eds.): Enzymes for carbohydrate engineering (Progress in Biotechnology) 199612 23-41 (Elsevier, Amsterdam, The Netherlands) ISBN: 978-0-44482408-0 DOI: 10.1016/S0921-0423(96)80360-1

[3] van der Veen, B. A.; van Alebeek, G.-J. W. M.; Uitdehaag, J. C. M.; Dijkstra, B. W.; Dijkhuizen, L.: The three transglycosylation reactions catalyzed by cyclodextrin glycosyltransferase from Bacillus circulans (strain 251) proceed via different kinetic mechanisms Eur. J. Biochem. 2000 267(3) 658-665 DOI: 10.1046/j.1432-1327.2000.01031.x

[4] Isao, K.; Yoshida, N.: Method of producing $\beta$ cyclodextrin 1996 US 5556775, United States Patent and Trademark Office https://patents. google.com/patent/US5556775A/en
[5] Shieh, W. J.; Hedges, A. R.: Process for producing alpha-cyclodextrin using cyclomaltodextrin glucanotransferase in presence of cyclohexane 1994 US 5326701, United States Patent and Trademark Office https://patents.google.com/patent/US5326701A/ en

[6] Yu, E. K. C.; Aoki, H.; Misawa, M.: Specific alpha-cyclodextrin production by a novel thermostable cyclodextrin glycosyltransferase Appl. Microbiol. Biotechnol. 1988 28(4-5) 377-379 DOI: 10.1007/BF00268199

[7] Wu, D.; Chen, S.; Wang, N.; Chen, J.; Wu, J.: Gamma-cyclodextrin production using cyclodextrin glycosyltransferase from Bacillus clarkii 7364 Appl. Biochem. Biotechnol. 2012 167(7) 1954-1962 DOI: 10.1007/s12010-012-9741-5

[8] Pishtiyski, I.; Popova, V.; Zhekova, B; Characterization of cyclodextrin glucanotransferase produced by Bacillus megaterium Appl. Biochem. Biotechnol. 2008144 263-272 DOI: 10.1007/s12010-007-8009-y

[9] Cheirsilp, B.; Kitcha, S.; Maneerat, S.: Kinetic characteristics of $\beta$-cyclodextrin production by cyclodextrin glycosyltransferase from newly isolated Bacillus sp. C26 Electron. J. Biotechnol. 2010 13(4) DOI: 10.2225/vol13-issue4-fulltext-6

[10] Bonilha, P. R. M.; Menocci, V.; Goulart, A. J.; Polizeli, M. L. T. M.; Monti, R.: Cyclodextrin glycosyltransferase from Bacillus licheniformis: Optimization of production and its properties Braz. J. Microbiol. 2006 37(3) 317-323 DOI: 10.1590/\$151783822006000300022

[11] Thombre, R. S.; Kanekar, P. P.: Synthesis of $\beta$ Cyclodextrin by Cyclodextrin glycosyl transferase produced by Bacillus licheniformis MCM-B1010 J. Microbiol. Biotech. Res. 2013 3(1) 57-60

[12] Matioli, G.; Zanin, G. M.; De Moraes, F. F.: Influence of substrate and product concentrations on the production of cyclodextrins by cgtase of Bacillus firmus, strain No. 37 Appl. Biochem. Biotechnol. 2002 98(1-9) 947-961 DOI: 10.1385/ABAB:98-100:19:947

[13] Gawande, B. N.; Goel, A.; Patkar, A. Y.; Nene, S. N.: Purifcation and properties of a novel raw starch degrading cyclomaltodextrin glucanotransferase from Bacillus firmus Appl. Microbiol. Biotechnol. 199951 504-509 DOI: 10.1007/s002530051424

[14] Pinto, F. S. T.; Flôres, S. H.; Ayub, M. A. Z.; Hertz, P. F.: Production of cyclodextrin glycosyltransferase by alkaliphilic Bacillus circulans in submerged and solid-state cultivation Bioprocess Biosyst. Eng. 2007 30(5) 377-382 DOI: 10.1007/s00449-007-0134-z

[15] Iyer, J. L.; Shetty, P.; Pai, J. S.: Immobilisation of cyclodextrin glucanotransferase from Bacillus circulans ATCC 21783 on purified seasand $J$. Ind. Microbiol. Biotechnol. 2003 30(1) 47-51 DOI: 10.1007/s10295-002-0009-x 
[16] Nishida, T.; Nakamura, A.; Masaki, H.; Uozumi, T.: Regulation of cyclodextrin glucanotransferase synthesis in Bacillus ohbensis FEMS Microbiol. Lett. 1997 149(2) 221-226 DOI: 10.1111/j.15746968.1997.tb10332.x

[17] Cami, P. H.; Majou, D. B.: Process for production of cyclodextrins 1994 US 5376537, United States Patent and Trademark Office https://patents. google.com/patent/US5376537A/en

[18] Shiosaka, M.: Heat stable cyclodextrin glycosyltransferase 1976 US 3988206, United States Patent and Trademark Office https://patents.google.com/ patent/Us3988206A/en

[19] Martín, M. T.; Plou, F. J.; Alcade, M.; Ballesteros, A.: Immobilization on Eupergit $\mathrm{C}$ of cyclodextrin glucosyltransferase ( CGTase ) and properties of the immobilized biocatalyst J. Mol. Catal. B Enzym. 2003 21(4-6) 299-308 DOI: 10.1016/S13811177(02)00264-3

[20] Wimmer, T.: Cyclodextrins in Ullmann's Encyclopedia of Industrial Chemistry 201211 DOI: 10.1002/14356007.e08_e02

[21] Uitdehaag, J. C. M.; Kalk, K. H.; van der Veen, B. A.; Dijkhuizen, L.; Dijkstra, B. W.: The cyclization mechanism of cyclodextrin glycosyltransferase (CGTase) as revealed by a $\gamma$-cyclodextrin-CGTase complex at 1.8- $\AA$ resolution J. Biol. Chem. 1999 274(49) 34868-34876 DOI: 10.1074/jbc.274.49.34868

[22] Thangadurai, D.; Sangeetha, J. (eds.): Industrial Biotechnology, Sustainable Production and Bioresource Utilization 2017 (Apple Academic Press, Oakville, Canada), ISBN: 978-1-771-88262-0

[23] Biwer, A.; Antranikian, G.; Heinzle, E.: Enzymatic production of cyclodextrins Appl. Microbiol. Biotechnol. 2002 59(6) 609-617 DOI: 10.1007/s00253002-1057-x

[24] Szejtli, J.: Introduction and general overview of cyclodextrin chemistry Chem. Rev. 1998 98(5) 1743-
1753 DOI: $10.1021 / \mathrm{cr} 970022 \mathrm{c}$

[25] Saenger, W.: Cyclodextrin inclusion compounds in research and industry Angew. Chem. Int. Ed. Engl. 1980 19(5) 344-362 DOI: 10.1002/anie.198003441

[26] Szejtli, J.: The cyclodextrins and their applications in biotechnology Carbohydr. Polym. 1990 12(4) 375-392 DOI: 10.1016/0144-8617(90)90088-A

[27] Del Valle, E. M. M.: Cyclodextrins and their uses: a review Process Biochem. 2004 39(9) 1033-1046 DOI: 10.1016/S0032-9592(03)00258-9

[28] Singh, M.; Sharma, R.; Banerjee, U. C.: Biotechnological applications of cyclodextrins Biotechnol. Adv. 2002 20(5-6) 341-359 DOI: 10.1016/S07349750(02)00020-4

[29] Li, S.; Li, W.; Xiao, Q. Y.; Xia, Y.: Transglycosylation of stevioside to improve the edulcorant quality by lower substitution using cornstarch hydrolyzate and CGTase Food Chem. 2013 138(2-3) 2064-2069 DOI: 10.1016/j.foodchem.2012.10.124

[30] Kochikyan, V. T.; Markosyan, A. A.; Abelyan, L. A.; Balayan A. M.; Abelyan, V. A.: Combined enzymatic modification of stevioside and rebaudioside A Appl. Biochem. Microbiol. 2006 42(1) 37-43 DOI: 10.1134/S0003683806010030

[31] DSMZ Nutrient agar (n.d.) Retrieved from https://www.dsmz.de/microorganisms/medium/pdf/ DSMZ_Medium1.pdf, date accessed: 2019.10

[32] Park, C. S.; Park, K. H.; Kim, S. H.: A rapid screening method for alkaline $\beta$-cyclodextrin glucanotransferase using phenolphthalein-methyl orangecontaining solid medium Agric. Biol. Chem. 1989 53(4) 1167-1169 DOI: 10.1080/00021369.1989.10869443

[33] Kaneko, T.; Kato, T.; Nakamura, N.; Horikoshi, K.: Spectrophotmetric determination of cyclization activity of $\beta$-cyclodextrin-forming cyclomaltodextrin glucanotransferase J. Jpn. Soc. Starch Sci. 1987 34(1) 45-48 DOI: 10.5458/jag1972.34.45 